\title{
Jornal Escolar e Compromisso Social em Tempos Pandêmicos: a Experiência do Projeto Folha Cefet
}

\section{School Journal and Social Commitment in Pandemic Times: The Experience of The Folha Cefet Project}

\section{Periódico Escolar y Compromiso Social en Tiempos de Pandemia: La Experiencia del Proyecto Folha Cefet}

\author{
iD 9 \\ Andreza Barboza Nora \\ Centro Federal de Educação Tecnológica Celso Suckow da Fonseca \\ iD 9 \\ Ana Letícia Couto Araujo \\ Centro Federal de Educação Tecnológica Celso Suckow da Fonseca
}

Resumo: O Folha Cefet é um jornal escolar que há cinco anos funciona como um projeto de extensão intercampi do Cefet/RJ. No presente trabalho, discorremos a respeito da confecção de uma edição especial do Folha Cefet - integralmente desenvolvida de forma remota - cuja linha editorial buscou contemplar a temática do enfrentamento da pandemia da Covid-19. Além de relatarmos todas as etapas de produção da edição, apresentamos, nos resultados, a avaliação dos estudantes participantes acerca do material veiculado e da própria atuação na realização das atividades. Também enfatizamos que a participação dos alunos nesse projeto de letramento possibilitou a inserção dos mesmos em práticas mediadas pela leitura e pela escrita por meio de uma rede de ações colaborativas e coletivas. Por fim, destacamos que o Folha Cefet não é somente um veículo midiático construído por estudantes e outros participantes da comunidade escolar, mas também um instrumento de ensino-aprendizagem e formação.

Palavras-chave: Jornal escolar. Folha Cefet. Covid-19. Projeto de letramento. Colaboração. 
Abstract: Folha Cefet is a school newspaper that has worked for five years as an intercampi extension project of Cefet/RJ. In the present work, we discuss the elaboration of a special edition of Folha Cefet - entirely developed remotely - whose editorial line sought to contemplate the theme of facing the Covid-19 pandemic. In addition to reporting all the production stages of the edition, we present, in the results, the evaluation of the participating students about the material conveyed and the performance of the activities. We also emphasize that the participation of students in this literacy project enabled their insertion in practices mediated by reading and writing through a network of collaborative and collective actions. Finally, we highlight that Folha Cefet is not only a media vehicle built by students and other participants in the school community, but also a teaching-learning and training tool.

Keywords: Scholar newspaper. Folha Cefet. Covid-19. Literacy project. Collaboration.

Resumen: Folha Cefet es un periódico escolar que desde hace cinco años funciona como proyecto de extensión intercampi en Cefet/RJ. En el presente trabajo, discutimos la realización de una edición especial de Folha Cefet - desarrollada íntegramente de forma remota - cuya línea editorial buscaba contemplar el tema del enfrentamiento a la pandemia Covid-19. Además de reportar todas las etapas de producción de la edición, presentamos, en los resultados, la evaluación de los estudiantes participantes sobre el material transmitido y su desempeño en la realización de las actividades. Destacamos también que la participación de los estudiantes en este proyecto de alfabetización permitió su inserción en prácticas mediadas por la lectura y la escritura a través de una red de acciones colaborativas y colectivas. Finalmente, destacamos que Folha Cefet no es solo un vehículo mediático construido por 
estudiantes y otros participantes de la comunidad escolar, sino también una herramienta de enseñanza-aprendizaje y formación. Palabras clave: Periódico escolar. Folha Cefet. Covid-19. Proyecto de alfabetización. Colaboración.

Data de submissão: 16/11/2020

Data de aprovação: 23/11/2020

3

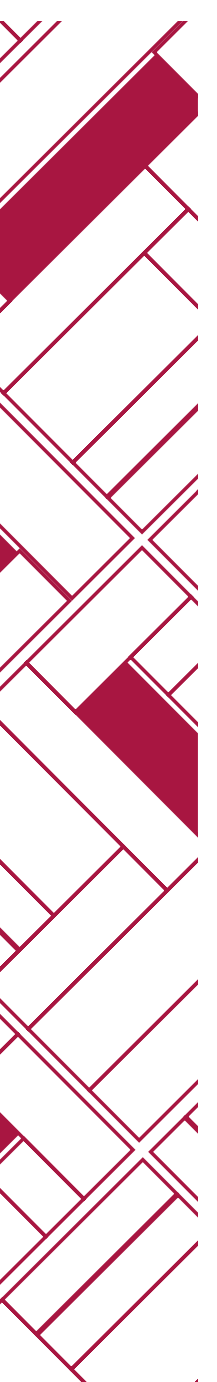




\section{Introdução}

O projeto de extensão Folha Cefet surgiu no ano de 2015, no campus Maria da Graça do Centro Federal de Educação Tecnológica (Cefet/RJ). O Cefet/RJ é uma instituição centenária que integra a atual Rede Federal de Educação Profissional, Científica e Tecnológica (RFEPCT) e possui dois campi situados na cidade do Rio de Janeiro (o campus-sede, no bairro Maracanã, e o campus Maria da Graça, também na zona norte) e outros seis campi no estado (Angra dos Reis, Itaguaí, Nova Friburgo, Nova Iguaçu, Petrópolis e Valença).

De natureza pluricurricular e multicampi, o Cefet/RJ atua na oferta de cursos técnicos integrados ao ensino médio, subsequentes (pós-médio), tecnológicos, de graduação e de pós-graduação lato sensu e stricto sensu (mestrado e doutorado), nas modalidades presencial e a distância. Para além das atividades regulares de ensino, a missão da instituição também contempla o desenvolvimento da extensão universitária e de atividades de pesquisa. Buscando atingir seus objetivos no tocante à indissociabilidade entre ensino, pesquisa e extensão, anualmente o Cefet/RJ disponibiliza editais que integram o Programa de Projetos e Bolsas de Extensão.

Em Nora (2019), publicizamos um relato no qual todo o processo de oficialização, implementação e desenvolvimento do projeto de extensão Folha Cefet foi explicitado. Nessa oportunidade, apresentamos as diferentes etapas de criação do jornal escolar, a organização da equipe de trabalho, algumas atividades de divulgação visando o engajamento de estudantes e servidores e resultados qualitativos e quantitativos obtidos no primeiro quadriênio de seu funcionamento. Destacamos, ainda, que o jornal Folha Cefet foi estruturado para funcionar primordialmente de modo on-line, permitindo o acesso a qualquer tempo e de qualquer espaço por todos os membros da comunidade escolar: um jornal a um clique. 
Jornal Escolar e Compromisso Social em Tempos Pandêmicos:

A Experiência do Projeto Folha Cefet

Andreza Barboza Nora • Ana Letícia Couto Araujo, et el...

Desde a sua criação, o Folha Cefet vem perseguindo o objetivo de divulgar as atividades desenvolvidas nos diferentes campi do Cefet/RJ, de propiciar uma maior integração entre os vários segmentos que compõem a comunidade acadêmica (alunos, professores, servidores técnico-administrativos e famílias), de ampliar os espaços para discussão de temas que emergem tanto do cotidiano escolar quanto do universo extraescolar e o de engajar os estudantes na produção de textos multissemióticos (ROJO, 2016, 2017) socialmente situados.

Por entendermos que o letramento (SOARES, 2012) na sociedade contemporânea demanda práticas dinâmicas, multimodais e plurais (ROJO, 2017), revisitamos os escritos de Freinet (1974) - primeiro teórico a sistematizar as potencialidades do trabalho pedagógico com a confecção de jornais - e a esses atribuímos uma nova roupagem, adaptada a diferentes transformações que o currículo sofreu no campo da linguagem, sobretudo com a incorporação das chamadas TIC (Tecnologias da Informação e Comunicação) no cotidiano das escolas.

Ainda que na sociedade contemporânea as novas tecnologias tenham dado início a um processo de transformação em certas práticas que envolvem ensino/aprendizagem, a contribuição de Freinet (1974) no tocante ao desenvolvimento do jornal escolar se mantém viva até hoje. Há décadas o autor já salientava que o movimento de cooperação era fundamental no trabalho pedagógico e que o jornal, ferramenta de caráter inovador à época, pressupunha um princípio cooperativo. Esse perfil, destacado como uma das vantagens sociais do jornal escolar pelo educador francês, é um dos fundamentos sobre os quais está assentada a concepção do Folha Cefet.

O nosso jornal escolar, desde a sua criação, foi hospedado em uma plataforma gratuita denominada wikijornal. Wikis são fer- 
Jornal Escolar e Compromisso Social em Tempos Pandêmicos:

A Experiência do Projeto Folha Cefet

Andreza Barboza Nora • Ana Letícia Couto Araujo, et el...

ramentas que se destacam pela capacidade de integrar conhecimento produzido por diferentes sujeitos, independente da sua localização geográfica. No que diz respeito à plataforma wikijornal, a grande vantagem é que as diferentes ferramentas disponibilizadas aos usuários cadastrados se configuram como suporte para a produção de conteúdo jornalístico. Diferente do que ocorre no desenvolvimento de blogs, em que cada usuário disponibiliza conteúdo em uma página particular da qual dispõe com total autonomia, no formato wiki os conteúdos podem ser criados de modo conjunto pelos colaboradores. Nesse sentido, cada matéria veiculada é fruto de negociação entre os participantes, que podem assumir papeis variados no desenvolvimento do trabalho: de redator, de revisor, de editor, de administrador. Ainda que um conteúdo ou outro seja enviado para o nosso jornal escolar a partir da iniciativa particular de um usuário, necessariamente o texto passará pela apreciação dos administradores, que poderão sugerir alterações antes de publicá-lo.

Em tempos de "normalidade sanitária", o perfil colaborativo do Folha Cefet já se mostrava promissor, pois o formato wiki do jornal está conectado com a realidade de grande parte dos estudantes que, em seus modos de interação, já se apropria rotineiramente de mídias sociais e linguagens tecnológicas ancoradas na colaboração. No presente ano, em que a pandemia da Covid-19 nos impôs o distanciamento social, a natureza do Folha Cefet (on-line e wiki) possibilitou que o projeto de extensão não tivesse suas atividades interrompidas, apesar da dinâmica de trabalho remoto implementada no Cefet/RJ ainda no mês de março.

No Cefet/RJ, as atividades regulares presenciais de ensino, pesquisa e extensão foram suspensas em todos os campi por meio de portaria $n^{\circ} 384$, de 27 de março de 2020. Entretanto, durante o próprio mês de março, no qual foi instituída a suspensão das ativi- 
Jornal Escolar e Compromisso Social em Tempos Pandêmicos:

A Experiência do Projeto Folha Cefet

Andreza Barboza Nora • Ana Letícia Couto Araujo, et el...

dades acadêmicas presenciais, os docentes receberam o aval institucional para dar continuidade à execução das atividades previstas em seus respectivos Planos Individuais de Trabalho por meio de expediente remoto. Assim como o quadro de professores, os servidores técnico-administrativos da instituição também foram submetidos ao regime de teletrabalho. Assim, todas as atividades planejadas e executadas pela coordenação do projeto de extensão Folha Cefet estiveram amparadas nas prerrogativas legais.

No início do mês de abril, os integrantes do projeto de extensão (estudantes do Ensino Médio Integrado) e as duas servidoras que o coordenam deram início à programação das atividades do jornal escolar. No presente relato, nosso propósito é trazer a público como o grupo organizou e efetivou suas ações durante o primeiro semestre de 2020 , destacando a produção e a divulgação de uma edição especial on-line cuja linha editorial, definida coletivamente, buscou contemplar demandas específicas da comunidade interna e externa relacionadas ao coronavírus e a seu enfrentamento. Para além de relatar nossas ações, pretendemos reforçar que a extensão universitária, em um momento de incertezas e dificuldades como o que estamos vivenciando no período pandêmico, assume a tarefa, mais que nunca, de traduzir para a sociedade o potencial das Instituições Federais de Ensino (IFEs) no que diz respeito à prestação de serviços, à assistência e ao compromisso social.

\section{A Edição Especial de Quarentena: Um Trabalho Feito a Muitas Mãos}

Em abril de 2020, quando a experiência ora relatada começou a ser planejada, a equipe do jornal escolar Folha Cefet era compos- 
Jornal Escolar e Compromisso Social em Tempos Pandêmicos:

A Experiência do Projeto Folha Cefet

Andreza Barboza Nora • Ana Letícia Couto Araujo, et el...

ta de nove estudantes do Ensino Médio integrado à Educação Profissional e duas coordenadoras - uma docente da Coordenação de Língua Portuguesa e Literatura Brasileira (COLIP) e uma pedagoga lotada na Direção de Ensino (DIREN). Era a primeira vez que os estudantes participavam do jornal, mesmo no caso dos veteranos. A dedicação ao projeto era voluntária, porquanto não conseguimos bolsa à ocasião. Entre os discentes participantes, havia três do $1^{\circ}$ ano (cursos técnicos de Administração e Estradas), outros três do $2^{\circ}$ ano (cursos técnicos de Informática e Elétrica), dois do $3^{\circ}$ ano (cursos técnicos de Administração e Meteorologia) e uma do $4^{\circ}$ ano (curso técnico de Meteorologia).

A comunicação entre os integrantes da equipe acontecia sobretudo pelo aplicativo gratuito Whatsapp, ferramenta que possibilitou a troca de mensagens e arquivos entre o grupo e o prosseguimento das atividades do projeto, não obstante o distanciamento físico imposto pela pandemia. A interação acontecia, na maior parte do tempo, no formato em que um falava para todos do grupo; entretanto, houve ocasiões em que a comunicação se deu entre uma das coordenadoras e um integrante em particular.

Paralelamente à troca virtual via Whatsapp, o grupo interagia ainda por meio de correio eletrônico (e-mail) e compartilhava documentos (textos, imagens, gráficos, apresentações etc.) que eram criados e/ou hospedados no Google Drive, no Microsoft Teams e no Canva. Em cada uma dessas plataformas, a coordenação do projeto criou uma conta com o login folhacefet, cujo acesso foi compartilhado com a equipe. Destarte, o manuseio das contas sempre foi uma prerrogativa de todos os que compunham o grupo, independente da função desempenhada: coordenador, bolsista ou voluntário.

A ideia de elaborar uma edição especial de quarentena do nosso jornal escolar surgiu em decorrência dos diferentes inte- 
Jornal Escolar e Compromisso Social em Tempos Pandêmicos:

A Experiência do Projeto Folha Cefet

Andreza Barboza Nora • Ana Letícia Couto Araujo, et el...

resses do grupo no concernente aos assuntos que abordaríamos naquele momento nas nossas mídias sociais. Ou seja, enquanto alguns gostariam de destacar o tema da saúde mental frente ao isolamento social, outros propuseram a divulgação de uma matéria sobre o novo coronavírus a partir da visão de especialistas. Ao mesmo tempo, havia da parte das coordenadoras do projeto o desejo de dar visibilidade às ações voluntárias que começaram a ser desenvolvidas por trabalhadores de diferentes campi Cefet/RJ no intuito de colaborar com a sociedade no enfrentamento da pandemia.

Após a manifestação dos integrantes da equipe com relação aos assuntos que gostariam de abordar naquele momento em que a pandemia do novo coronavírus tinha acabado de nos impor o isolamento social, definiu-se o formato de uma publicação digital que foi chamada de "Edição especial de quarentena". Em seguida, o grupo começou a mobilização para contatar os profissionais que seriam entrevistados por ocasião da produção da edição especial. Paralelamente, anunciamos nas nossas redes sociais o lançamento futuro da publicação, contando com as artes visuais e os textos de divulgação confeccionados também pela equipe. Sob a orientação das coordenadoras do projeto, o grupo se organizou para que o planejamento e a execução da nossa proposta fossem desenvolvidos com a participação de todos, com atenção aos prazos definidos para cada etapa.

Considerando as diferentes seções que comporiam a nossa edição especial, a equipe se dividiu para que fosse possível dar andamento a todas elas paralelamente. Isto implicou um esforço colaborativo no sentido de contatar pessoas que seriam entrevistadas, angariar a participação dos nossos seguidores nas redes sociais e organizar o material que recebíamos por áudio ou texto.

Após o aceite das duas profissionais convidadas para uma entrevista remota - uma psicóloga servidora do Cefet/RJ e uma 
Jornal Escolar e Compromisso Social em Tempos Pandêmicos:

A Experiência do Projeto Folha Cefet

Andreza Barboza Nora • Ana Letícia Couto Araujo, et el...

ex-professora de Biologia do Ensino Médio do Cefet/RJ -, o grupo utilizou as redes sociais do nosso jornal para uma breve apresentação do currículo de cada uma e um convite aos nossos seguidores para que participassem nos enviando perguntas que seriam respondidas pelas entrevistadas. A respeito do teor das entrevistas, a conversa com a psicóloga, doutora em saúde coletiva, girou em torno dos efeitos do isolamento social na nossa saúde mental, enquanto com a professora, doutora em biologia celular e molecular, tivemos a oportunidade de discutir a importância da ciência e da divulgação científica no contexto de uma pandemia, além de conhecer melhor o novo coronavírus, sua transmissão e as medidas necessárias para contê-lo.

Em paralelo, divulgamos nas nossas redes sociais uma chamada aberta aos nossos seguidores interessados na escrita de um artigo de opinião, charge ou tirinha, em torno do tema "negacionismo e fake news no contexto da pandemia do novo coronavírus no Brasil". Dois ex-alunos do Cefet/RJ, atualmente estudantes universitários, enviaram seus artigos para o e-mail da equipe do jornal e tiveram seus textos publicados na nossa edição especial, após revisão gramatical pelas coordenadoras do projeto. A seção na qual os artigos foram inseridos contou ainda com uma charge feita por um professor do campus Realengo do Colégio Pedro II. Com a proposta de abrir o diálogo com os leitores do nosso jornal acerca desses artigos, sugerimos o envio de uma "carta do leitor", caso alguém se propusesse a comentar ou avaliar criticamentetais textos.

Somou-se ao conteúdo da edição especial o conto escrito por uma integrante da equipe, estudante do $3^{\circ}$ ano do Ensino Médio no curso técnico de Administração. Partiu da aluna a ideia de incluir um texto literário, que ela mesma se propôs a escrever. A plataforma Wiki onde nosso jornal é hospedado conta com uma seção chamada Literariedade, de modo que a equipe considerou provei- 
Jornal Escolar e Compromisso Social em Tempos Pandêmicos:

A Experiência do Projeto Folha Cefet

Andreza Barboza Nora • Ana Letícia Couto Araujo, et el...

tosa e enriquecedora a inclusão de um texto de caráter literário na nossa edição especial. Do ponto de vista das coordenadoras, em particular, considerando a natureza educativa da função que desempenham junto aos estudantes, foi - e sempre será - motivo de grande satisfação ensejar a produção textual de um aluno.

A seção de abertura da edição especial trouxe a público as diversas iniciativas desenvolvidas, em caráter voluntário, no âmbito do Cefet/RJ, por diferentes atores institucionais, a partir da chegada do novo coronavírus ao estado do Rio de Janeiro. Com a suspensão das atividades acadêmicas e administrativas presenciais, servidores docentes e técnicos-administrativos, qualificados em diferentes áreas de formação, deram início à empreitada de colaborar com a sociedade no enfrentamento da pandemia. Entre as ações desenvolvidas, podemos citar a produção de equipamentos de proteção individual, como máscaras e álcool 70\%, e a manutenção e o reparo de ventiladores mecânicos de hospitais públicos. As iniciativas se voltaram a atender comunidades pobres e sistemas de saúde pública em várias regiões do estado do Rio de Janeiro.

Após definir a sequência e o título das seções, haja vista a variedade de gêneros textuais que tínhamos em mãos, a escrita de um breve editorial e do sumário encerrou nosso trabalho de produção textual. A etapa seguinte foi a diagramação desse material do qual dispúnhamos.

Uma vez concluída a diagramação, criamos no Google Drive o link de acesso à edição especial, o qual foi amplamente divulgado pela equipe nas redes sociais do jornal (Instagram e Facebook), na plataforma Wiki em que o Folha Cefet está hospedado (www.wikijornal/folhacefet), assim como entre os nossos contatos pessoais.

Na figura 1, disposta na sequência, é possível ver o layout da primeira página da edição especial de quarentena do Folha Cefet. O leitor ou a leitora deste relato que tiver interesse em conferir 
Jornal Escolar e Compromisso Social em Tempos Pandêmicos:

A Experiência do Projeto Folha Cefet

Andreza Barboza Nora • Ana Letícia Couto Araujo, et el...

a edição completa do jornal, tornada pública em 22 de maio de 2020, pode fazê-lo acessando o seguinte link: http://bit.ly/3e9kwsr.
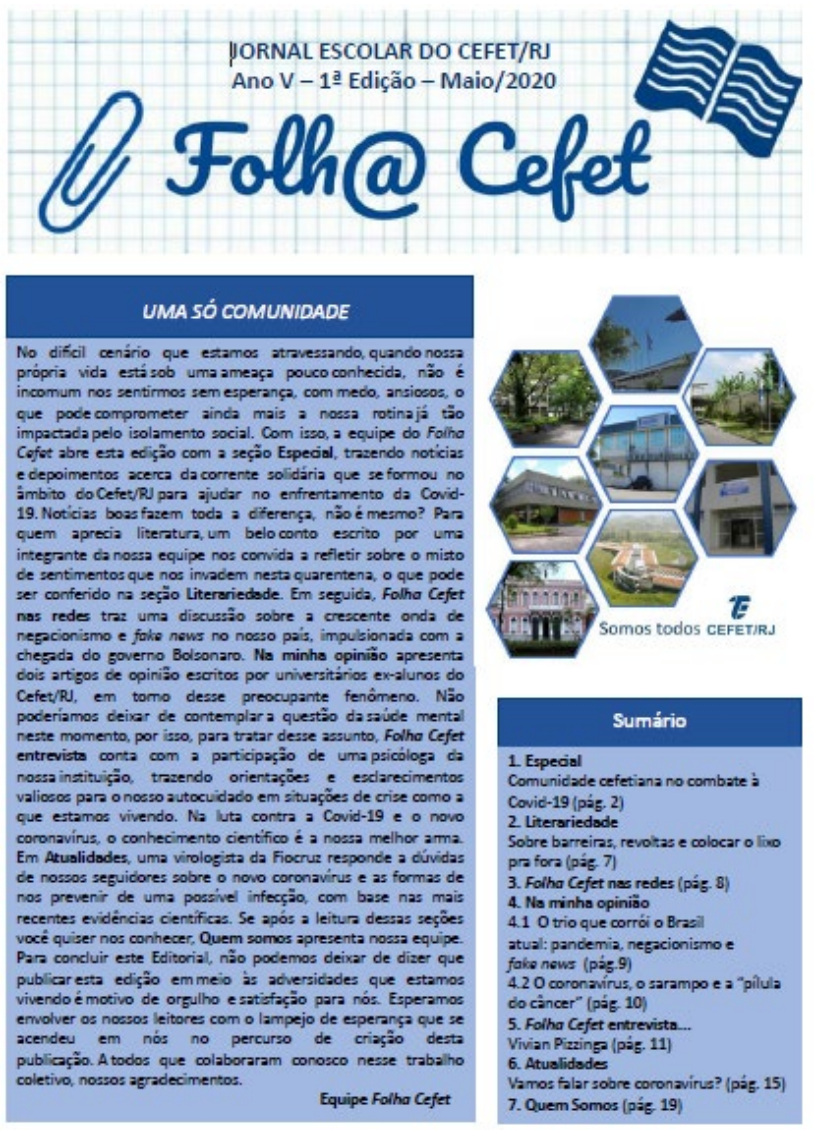

Figura 1- Capa da edição especial de quarentena do jornal Folha Cefet

Fonte: Acervo próprio

\section{Resultados}

Uma das premissas sobre a qual se assenta o projeto de extensão Folha Cefet é primar pela potencialização, nos estudantes que integram a equipe, do exercício do protagonismo social. Nesse sentido, além de poderem participar ativamente de todo o processo de construção do jornal escolar - desde a definição da linha editorial até a divulgação do trabalho final em diferentes mídias - os integrantes também tiveram a oportunidade de avaliar tanto 
Jornal Escolar e Compromisso Social em Tempos Pandêmicos:

A Experiência do Projeto Folha Cefet

Andreza Barboza Nora • Ana Letícia Couto Araujo, et el...

a edição especial divulgada para a comunidade no mês de maio quanto a própria atuação nas atividades até então desenvolvidas.

Para obter o feedback dos estudantes, as coordenadoras do projeto elaboraram, via ferramenta Google Docs, um formulário de avaliação contendo dez questões, entre perguntas de múltipla escolha e abertas. Com os questionamentos realizados, buscaram gerar compreensão, de modo geral, a respeito: a) da percepção dos discentes sobre o nível de engajamento nas ações relativas à confecção da edição especial, b) do atendimento ou não das expectativas prévias de cada um à participação no projeto de extensão, c) da análise qualitativa da edição veiculada para a comunidade na perspectiva dos alunos participantes.

Todos os estudantes responderam ao questionário proposto e a apreciação do conjunto de respostas pela coordenação evidenciou que dois terços deles avaliaram como satisfatória a participação na confecção da edição de quarentena. Paralelamente, apenas um terço não se considerou suficientemente ativo nas atividades que giraram em torno dela. Como justificativa para um engajamento abaixo do que inicialmente esperavam, os alunos apontaram questões relativas à saúde mental como principal fator.

No que diz respeito à questão sobre as expectativas criadas, todos afirmaram que elas foram atendidas no decurso do trabaIho. A resposta positiva unânime obtida neste item indica a satisfação das expectativas dos integrantes em relação às propostas e ações do projeto. Esse é um dado bastante relevante para a coordenação, pois além de refletir o contentamento dos estudantes no momento da resposta, tem caráter preditor quanto à permanência deles nas atividades do jornal nos meses subsequentes.

Quando indagados sobre as impressões que tiveram acerca da qualidade da edição produzida coletivamente pela equipe, os que realizaram a leitura completa teceram diferentes comentá- 
Jornal Escolar e Compromisso Social em Tempos Pandêmicos:

A Experiência do Projeto Folha Cefet

Andreza Barboza Nora • Ana Letícia Couto Araujo, et el...

rios, reproduzidos na sequência: "Gostei bastante! Nós nos saímos muito bem", "Pra quem tem gosto pela leitura, acho que foi informativo", "Fiquei bem feliz em ver a evolução que tivermos em tão pouco tempo, criar essa edição foi um desafio com as entrevistas, mas nós superamos e fizemos tudo com excelência", "Gostei bastante", "Muito boa". Essas respostas discursivas dos respondentes denotam que avaliaram positivamente o conteúdo produzido pelo Folha Cefet, havendo destaque tanto para o caráter informativo que a edição especial assumiu quanto para o empenho do grupo no desenvolvimento da mesma.

Para além dos resultados oriundos da análise das respostas ao questionário, também é possível empreender uma breve avaliação sobre os resultados relativos ao percurso formativo dos estudantes. Isso porque o desenvolvimento do Folha Cefet orienta-se pela perspectiva da dupla face do jornal a que se referiu Bonini (2011): ele não é somente um veículo midiático construído por alunos para a comunidade escolar, mas também um instrumento de ensino-aprendizagem.

Na medida em que busca refletir as práticas sociais que envolvem a confecção de um jornal convencional, a participação no projeto de extensão possibilita que os estudantes pratiquem o letramento digital e jornalístico. Ao se debruçarem sobre a produção e a edição de matérias que contemplam diferentes gêneros de jornais tradicionais (editorial, artigo de opinião, entrevista, reportagem, divulgação científica), os alunos têm a oportunidade de aprofundar seus conhecimentos sobre essa mídia. Nesse sentido, durante todas as etapas de confecção do jornal, os estudantes se apropriam de práticas plurais e multimodais (ROJO, 2017) integradoras de um projeto de letramento (KLEIMAN, 2000) que extrapola espaços, recursos e horários específicos da instituição de ensino e da sala de aula. 
Jornal Escolar e Compromisso Social em Tempos Pandêmicos:

A Experiência do Projeto Folha Cefet

Andreza Barboza Nora • Ana Letícia Couto Araujo, et el...

Como participantes desse projeto de letramento, os alunos têm a possibilidade de se inserirem em práticas mediadas pela leitura e pela escrita por meio de uma rede de ações colaborativas e coletivas que promovem um desdobramento de motivações provenientes de interesses da vida cotidiana. No caso da edição especial de quarentena publicada pelo Folha Cefet, a temática da pandemia do coronavírus foi o pano de fundo para a produção de textos cuja finalidade foi muito além de comprovar e mensurar suas competências de leitura e escrita: as matérias produzidas assumiram funções sociais que ultrapassaram os muros do Cefet/RJ.

A confecção da edição especial em um período que demandou uma organização e estruturação de modo integralmente virtual ao mesmo tempo em que representa a solidificação do Folha Cefet como uma mídia decorrente de atividades significativas da linguagem, também demonstra um amadurecimento do letramento midiático (BUCKINGHAM, 2010) dos estudantes e das coordenadoras do projeto. Prova disso é que antes do desenvolvimento do trabalho alguns participantes desconheciam plataformas como o Canva, nunca haviam realizado um compartilhamento de arquivo por nuvem, faziam uso limitado de ferramentas do Instagram. No decurso das atividades, enquanto alguns manipularam pela primeira vez arquivos de imagem e texto fora dos tradicionais programas do pacote office, outros aperfeiçoaram técnicas de compartilhamento de arquivos via Google Drive e/ou Whatsapp. Parte do grupo também estabeleceu o primeiro contato com a plataforma Teams, disponibilizada gratuitamente para todos os servidores e estudantes do Cefet/RJ. Com a apropriação desse recurso, foi possível editar de forma conjunta alguns textos que seriam futuramente publicados no jornal e, ainda, criar um repositório de imagens tratadas anteriormente em outros sítios, como o Canva. 
Jornal Escolar e Compromisso Social em Tempos Pandêmicos:

A Experiência do Projeto Folha Cefet

Andreza Barboza Nora • Ana Letícia Couto Araujo, et el...

Para além do progresso do letramento digital instrumental representado pelo emprego desses novos recursos das mídias disponíveis, também é importante salientar a maturação da consciência acerca de questões como autoridade e confiabilidade, uma vez que, enquanto produtores de conteúdo midiático para a comunidade interna e externa, os participantes precisam estar atentos à qualidade da informação que está sendo difundida.

Daí a busca por interlocutores especialistas altamente qualificados para a produção da matéria de divulgação científica sobre o coronavírus e também da entrevista sobre a saúde mental em tempos pandêmicos.

Também é preciso destacar que a participação no Folha Cefet, um projeto de letramento de natureza midiática, configura-se como um caminho efetivo para que os estudantes possam construir, de modo gradativo, um aparato analítico crítico capaz de desnaturalizar o discurso midiático, identificando, assim, valores, ideologias e motivações em seus mais diversos conteúdos, digitais ou não. Torna-se mais natural compreender o discurso midiático de forma sistematizada quando se tem a chance de refletir sobre ele a partir de uma posição ativa, de quem não somente consome, mas também produz mídia.

Em última análise, cabe pontuar que estudantes e coordenadoras, na medida em que propagam o jornal pela comunidade e se relacionam via ações alicerçadas em diferentes gêneros textuais, não se limitam a fazer parte de um projeto letramento: é plausível dizer que todos assumem o papel de agentes de letramento (KLEIMAN, 2007). Embora não seja possível determinar quantas pessoas fizeram a leitura completa da edição especial publicada, por meio dos recursos oferecidos pela plataforma wiki e pelo site bitly, foram contabilizados ao menos 450 acessos aos links compartilhados. Esse é um resultado expressivo, considerando-se que toda a divulgação foi realizada de forma remota e virtual. 


\section{Considerações finais}

No belo poema Tecendo a manhã, do poeta pernambucano João Cabral de Melo Neto, o sujeito lírico é categórico: “Um galo sozinho não tece uma manhã: ele precisará sempre de outros galos". A metáfora contida no poema é representativa do sentimento que nos moveu durante a experiência relatada neste artigo. Se a colaboração sempre foi a tônica do jornal escolar Folha Cefet, a experiência aqui relatada é emblemática nesse sentido.

Por ocasião do trabalho, vivíamos um tempo único na nossa existência, atravessado pelo clima de incertezas diante da pandemia do novo coronavírus, recém-chegado ao nosso país. Com nossa interação frontalmente afetada pelo isolamento social, o uso das tecnologias digitais foi condição sine qua non para o desenvolvimento das atividades. Todavia, a disponibilidade e a qualidade dos recursos tecnológicos não eram as mesmas para todos da equipe, de maneira que o nível de participação sofreu os impactos decorrentes dessa desigualdade.

Conforme dissemos nos resultados, um terço dos alunos participantes destacaram a questão da saúde mental como fator responsável por uma atuação aquém do que eles próprios esperavam inicialmente. Nós não sabíamos exatamente quais eram as dificuldades que enfrentavam em face da pandemia - fosse de ordem material, emocional ou afetiva -, mas acreditamos no potencial do trabalho colaborativo como forma de, inclusive, proporcionar algum tipo de suporte emocional à equipe por nós coordenada. Sem dúvida, nós fomos as primeiras beneficiadas por esse "convívio".

Como se pode ler ainda nos resultados, os depoimentos dos alunos ao avaliarem o trabalho confirmaram o quanto foi significativo para eles conseguir produzir o material que levou o nome deles estampado, não obstante o cenário adverso. Para as coorde- 
Jornal Escolar e Compromisso Social em Tempos Pandêmicos:

A Experiência do Projeto Folha Cefet

Andreza Barboza Nora • Ana Letícia Couto Araujo, et el...

nadoras, o feedback positivo dos estudantes somado ao resultado expressivo de visualização da edição especial publicada são indicativos do êxito logrado pela equipe. Inspiradas no pensamento de Paulo Freire (2005, p. 57), compreendemos o produto do nosso trabalho como um empreendimento cultural que se desprende de nós, mas nos deixa a sua marca e nos transforma.

Desde que a ideia de criar uma edição especial de quarentena veio à tona, tínhamos ciência do compromisso que seria assumido pela equipe, sobretudo porque envolveria a participação de pessoas convidadas a colaborar conosco nesse desafio. Uma das nossas entrevistadas, por exemplo, estava em trabalho de campo, envolvida diretamente com as pesquisas sobre o novo coronavírus. Não foi tarefa simples acessá-la nesse contexto.

Contudo, para além das dificuldades, temos a certeza de que a escola pública por nós representada, por meio da experiência aqui descrita, fez a diferença na vida escolar ou profissional dos integrantes da nossa equipe. Aliado ao propósito didático-pedagógico imanente aos objetivos do jornal escolar Folha Cefet está o compromisso político com a oferta de uma educação pública de qualidade aos nossos estudantes e com a extensão de nossas produções e práticas à sociedade da qual fazemos parte.

\section{Referências}

BONINI, A. JORNAL ESCOLAR: GÊNEROS E LETRAMENTO MIDIÁTICO NO ENSINO-APRENdizagem de linguagem. Revista Brasileira de Linguística Aplicada. Belo HorlZONTE, V. 11, N. 1, P. 149-175, 2011. DISPONÍVEL EM: HTTP://WWW.SCIELO.BR/PDF/ RBLA/V11 N1/V11 N1A09.PDF. ACESSO EM: 09 oUt. 2020.

BUCKINGHAM, D. CULTURA DIGITAL, EDUCAÇÃO MIDIÁTICA E O LUGAR DA ESCOLARização. Educ. Real., Porto Alegre, v. 35, N. 3, P. 37-58, Set./dezz., 2010. 
Jornal Escolar e Compromisso Social em Tempos Pandêmicos:

A Experiência do Projeto Folha Cefet

Andreza Barboza Nora • Ana Letícia Couto Araujo, et el...

FREINET, C. O Jornal Escolar. Lisboa: Estampa, 1974.

FREIRE, P. Educação e mudança. 28. ed. Rio de Janeiro: Paz e Terra, 2005.

KLEIMAN, A. O PROCESSO DE ACULTURAÇÃO PELA ESCRITA: ENSINO DA FORMA OU APRENDIZAGEM DA FUnçÃO? IN: KLEIMAN, A. B; SIGNORINI, I. (ORGS.). $O$ ENSINO e A formação do Professor: alfabetização de jovens e adultos. Porto Alegre: ARTMED, 2000.

KLEIMAN, A. B. LeTRAMENTO E SUAS IMPLICAÇÕES PARA O ENSINO DE LÍNGUA MATERNA. Signo. Santa CRUZ do Sul, v. 32, N. 53, P. 1-25, deZ, 2007.

NORA, A. Folha Cefet: o jornal escolar do campus Maria da Graça. R. UFG, GoIÂNIA, V. 19, 1-12, E-56340, 2019. DISPONÍVEL EM: HTTPS://WWW.REVISTAS.UFG. BR/REVISTAUfG/ARTICLE/VIEW/56340 ACESSO EM: 09 oUt. 2020.

ROjO, R. Letramentos múltiplos, escola e inclusão social. São Paulo:

PARÁBOLA, 2017.

ROjO, R. Pedagogia dos Multiletramentos. In: MOURA, E.; ROjO, R. (orgs.) Multiletramentos na escola. São Paulo: Parábola, 2016.

SOARES, M. Letramento: um tema em três gêneros. 3. ed. Belo Horizonte: AutêntICA EdITORA, 2012. 